\title{
ENDOSCOPY
}

\section{NORCCAP (Norwegian colorectal cancer prevention): a randomised trial to assess the safety and efficacy of carbon dioxide versus air insufflation in colonoscopy}

\author{
M Bretthauer, E Thiis-Evensen, G Huppertz-Hauss, L Gisselsson, T Grotmol, \\ E Skovlund, G Hoff
}

See end of article for authors' affiliations

.....................

Correspondence to: DrM Bretthaver,

Norwegian Colorectal

Cancer Prevention (NORCCAP), Telemark Central Hospital, N-3906

Porsgrunn, Norway; michael.bretthaver@ tss.telemax.no

Accepted for publication 9 July 2001

\begin{abstract}
Background: To eliminate the risk of combustion during electrosurgical procedures and to reduce patient discomfort, carbon dioxide $\left(\mathrm{CO}_{2}\right)$ insufflation has been recommended during colonoscopy. However, air insufflation is still the standard method, perhaps due to the lack of suitable equipment and shortage of randomised studies.

Aims: This randomised controlled trial was conducted to assess patient tolerance and safety when using $\mathrm{CO}_{2}$ insufflation during colonoscopy.

Patients: Over an eight month period a successive series of patients referred for a baseline colonoscopy due to findings in a flexible sigmoidoscopy screening trial were randomly assigned to the use of either air or $\mathrm{CO}_{2}$ insufflation during colonoscopy.

Methods: End tidal $\mathrm{CO}_{2}\left(\mathrm{ETCO}_{2}\right)$, a non-invasive parameter of arterial $\mathrm{pCO}_{2}$, was registered before and repeatedly during and after the examination. The patient's experience of pain during and after the examination was registered using a visual analogue scale (VAS). Sedation was not used routinely. Results: $\mathrm{CO}_{2}$ insufflation was used in 121 patients $(51 \%)$ and air in 119 patients (49\%). The groups were similar in age, sex, and caecal intubation rate. No rise in $\mathrm{ETCO}_{2}$ was registered. There were statistically significant differences in VAS scores between the groups with less pain reported when using $\mathrm{CO}_{2}$.

Conclusions: This randomised study of unsedated patients shows that $\mathrm{CO}_{2}$ insufflation is safe during colonoscopy with no rise in $\mathrm{ETCO}_{2}$ level. $\mathrm{CO}_{2}$ was found to be superior to air in terms of pain experienced after the examination.
\end{abstract}

n 1952, the American Journal of Surgery focused on the potential risk of explosion in the rectum during electrosurgical polypectomy. Three cases of explosions were presented, suggested to be caused by the presence of intraluminal explosive gas mixtures. ${ }^{1}$ One year later, Becker was the first to recommend using carbon dioxide $\left(\mathrm{CO}_{2}\right)$ insufflation to eliminate the risk of gas explosion during electrocoagulation in the colon. ${ }^{2}$

In 1986, Christopher B Williams described the superiority of $\mathrm{CO}_{2}$ in reducing the risk of gas combustion, its rapid absorption from the colon allowing double contrast barium enema examination to be performed on the same day if required, and the minimal interference of $\mathrm{CO}_{2}$ with colonic blood flow, reducing the risk of ischaemia. ${ }^{3}$ It has also been claimed that $\mathrm{CO}_{2}$ insufflation during colonoscopy could reduce pain experienced by patients during and after the procedure. ${ }^{3}$

Nevertheless, air insufflation has remained the standard method in most centres around the world. Until recently, this was partly due to lack of $\mathrm{CO}_{2}$ insufflators adequately tailored for colonoscopy. To our knowledge however there is a striking absence of randomised trials comparing $\mathrm{CO}_{2}$ and air in colonoscopy.

The use of $\mathrm{CO}_{2}$ in colonoscopy could interfere with the body's acid-base balance, as shown in laparoscopic surgery where a rise in arterial $\mathrm{pCO}_{2}$ is frequently observed after $\mathrm{CO}_{2}$ insufflation. ${ }^{45}$ It is therefore also important to assess the safety of $\mathrm{CO}_{2}$ insufflation during colonoscopy.

As recently described, colonoscopy is increasingly considered to be the future approach in colorectal cancer screening. ${ }^{6}$ It is therefore of great importance to develop methods that can reduce patient discomfort and thus contribute to better public acceptance for colonoscopy.
This trial compared $\mathrm{CO}_{2}$ with air insufflation in colonoscopy with regard to patient pain during and after the examination and investigated whether $\mathrm{CO}_{2}$ insufflation leads to a rise in body $\mathrm{CO}_{2}$ level.

\section{METHODS \\ Attendees}

The NORwegian Colorectal CAncer Prevention (NORCCAP) study is an ongoing screening trial for the prevention of colorectal cancer. Fourteen thousand presumptively healthy men and women, aged 55-64 years, living in two separate areas in Norway are randomly drawn from the population registry and invited to undergo a screening flexible sigmoidoscopy (FS) for colorectal adenomas and cancer. Patients with former colonic resections, severe heart or lung disease (New York Heart Association (NYHA) III-IV), or ongoing treatment for malignant disease are excluded. Bioptically verified adenoma at screening FS, irrespective of size, qualifies for a baseline colonoscopy with polypectomy, to be performed within 6-8 weeks after FS.

NORCCAP participants referred for colonoscopy between October 1999 and April 2000 (267 patients) were included in the present study. All examinations were performed by one of three experienced endoscopists. According to recently published guidelines, ${ }^{7}$ colonoscopies were performed without any

Abbreviations: $\mathrm{ETCO}_{2}$, end-tidal carbon dioxide; FS, flexible sigmoidoscopy; NORCCAP, NORwegian Colorectal CAncer Prevention; NYHA, New York Heart Association; VAS, visual analogue scale. 
routine use of sedation. However, on demand medication with intravenous midazolam was given if indicated, as judged by the endoscopist. For bowel cleansing, a 4 litre polyethylene glycol solution was used, taken orally on the day before the examination.

\section{Randomisation}

Participants referred for colonoscopy were successively assigned to appointments as referrals were received and no sessions were available other than for participants in the NORCCAP screening study. Whole day sessions for colonoscopy were randomised for $\mathrm{CO}_{2}$ or air insufflation, using sealed envelopes. Randomisation of whole sessions rather than individual patients was done to avoid unblinding by change of gas couplings between patients. Both participants and endoscopists were blinded with regard to which gas was being used.

\section{Endoscopic examination}

Procedures were performed using Olympus video colonoscopes (Olympus, Hamburg, Germany). However, the standard gas/water valves of the endoscopes which only redirect a continuous gas flow into the gut lumen or atmospheric air, were replaced with another type of valve (MIJ-521, Olympus) preventing gas leakage into the environment. To administer gas into the colon, the valve button had to be pushed halfway down. $\mathrm{CO}_{2}$ or air was administered using two different pressure and flow controlled devices connected to the $\mathrm{CO}_{2}$ and air reservoirs provided (Endoscopic $\mathrm{CO}_{2}$ Regulator; Key Med Ltd (Southend-on-Sea, Essex, UK) for $\mathrm{CO}_{2}$, Norsk Hydro Ltd (Oslo, Norway) for air). The endoscopy assistant was responsible for switching on and off the $\mathrm{CO}_{2}$ and air devices, respectively. To prevent unblinding, the devices were placed behind the endoscopy rack and hidden from the view of the endoscopist.

\section{End-tidal $\mathrm{CO}_{2}$ measurements}

End-tidal (ET) $\mathrm{CO}_{2}$ has been shown to give adequate approximations of arterial $\mathrm{pCO}_{2}$ in spontaneously breathing adults and is therefore a good and commonly used non-invasive method of expressing arterial $\mathrm{pCO}_{2}{ }^{8}$

However, before starting the trial we conducted $\mathrm{ETCO}_{2}$ measurements and arterial $\mathrm{pCO}_{2}$ samples simultaneously on five consecutive patients. The two methods were comparable, with a maximum deviation of the $\mathrm{ETCO}_{2}$ value of only $0.2 \mathrm{kPa}$. Additionally, we performed repeated measurements within the group of investigators to test the validity of the method, with no evidence of method failure.

ETCO $_{2}$ was measured successively: (1) at the start of each examination, (2) when the endoscope had reached the caecum, (3) when the rectum was passed during withdrawal, and (4) 10 minutes after finishing the examination. At these measuring points, patients were asked to take a deep breath and to expire deeply and slowly through the mouthpiece of the provided mainstream infrared capnograph (Novametrix Ltd, Wallingford, Connecticutt, USA). The endoscopy assistant performed the measurements and registered the readings. Both the participant and endoscopist were blinded to the results.

\section{Measurement of pain}

Pain was registered on a questionnaire given to participants immediately after the examination. A $100 \mathrm{~mm}$ visual analogue scale (VAS) was used, ranging from "no pain" on the left to "pain as bad as it could be" on the right end. Participants were asked to score the amount of pain experienced at one, three, six, and 24 hours after the examination. In addition, the questionnaire contained a similar VAS scale for the amount of pain experienced during the examination. Once completed, questionnaires were returned by mail to the screening centre.
Table 1 Participant and examination characteristics in the $\mathrm{CO}_{2}$ and air groups

\begin{tabular}{lcc}
\hline & $\begin{array}{c}\mathrm{CO}_{2} \text { group } \\
(\mathrm{n}=121)\end{array}$ & $\begin{array}{c}\text { Air group } \\
(\mathrm{n}=119)\end{array}$ \\
\hline Sex (M/F) & $77 / 44$ & $75 / 44$ \\
Mean age (y) & 59.5 & 59.6 \\
Caecum reached (No (\%)) & $109 \quad(90)$ & $108 \quad(90)$ \\
$\begin{array}{c}\text { Time to caecum (min) (mean } \\
(\mathrm{SD}))^{*}\end{array}$ & $13.1(7.6)$ & $15.2(8.5)$ \\
\hline${ }^{*} \mathrm{p}=0.09$. & & \\
\hline
\end{tabular}

\section{Statistical analysis}

A pilot study was conducted to estimate the SDs of the pain and $\mathrm{ETCO}_{2}$ measurements, respectively.

Regarding the pain measurements, with an assumed SD of $30 \mathrm{~mm}$, we estimated that 240 patients were needed to achieve at least $95 \%$ power to detect a $15 \mathrm{~mm}$ difference in VAS between the two groups, which was considered to be clinically important. Assuming that the difference in $\mathrm{ETCO}_{2}$ would have to be $>0.5 \mathrm{kPa}$ to be clinically important (SD 0.6), the power to detect this with 150 patients was $95 \%$.

For statistical analysis of repeated measurements of pain and $\mathrm{ETCO}_{2}$, ANOVA for repeated measures was used. Some variables were not normally distributed and thus the Wilcoxon rank sum test was used as a supplementary analysis to compare groups at each time point. The proportion of individuals reporting no pain on the VAS was compared at each time point using the $\chi^{2}$ test. Statistical significance was defined as $p \leqslant 0.05$. Only two sided tests were used. Statistical analyses were performed using SPSS 9.0.

\section{Ethics}

The regional ethics committee approved the study protocol. Informed consent was obtained from all participants before entering the trial.

\section{RESULTS}

A total of 267 patients were randomised and examined; 249 patients $(93 \%)$ completed the questionnaire. Ten patients (seven in the air group and three in the $\mathrm{CO}_{2}$ group; $\mathrm{p}<0.01$ ) received sedation and were excluded from further analysis. Thus 240 patients were included in the study; 121 (51\%) were examined using $\mathrm{CO}_{2}$ insufflation and air was used in 119 patients $(49 \%)$. There were no differences in baseline characteristics between the two groups (table 1). No statistically significant differences were observed between endoscopists. There was a trend towards more rapid caecal intubation in patients in the $\mathrm{CO}_{2}$ group (table 1 ).

The only complication registered was one perforation requiring colonic resection (air group). This occurred after snare polypectomy of a large sessile adenoma with severe dysplasia in the sigmoid colon.

\section{End-tidal $\mathrm{CO}_{2}$}

According to power estimates it was considered sufficient to measure $\mathrm{ETCO}_{2}$ in a limited number of patients and hence $\mathrm{ETCO}_{2}$ measurements were restricted to the first 156 examinations performed without sedation, including 81 patients in the air group and 75 patients in the $\mathrm{CO}_{2}$ group. As shown in fig 1, there was no rise in $\mathrm{ETCO}_{2}$ during or after the examination in any group. On the contrary, we observed a significant reduction in $\mathrm{ETCO}_{2}$ levels during examination in both groups $(\mathrm{p}<0.001)$. This reduction was more pronounced when air was used. The time point differences between the groups reached significance only for $\mathrm{ETCO}_{2}$ readings registered towards the end of the examination $(p=0.01)$ (fig 1 ). However, this difference was estimated to be $0.28 \mathrm{kPa}(95 \%$ confidence interval (CI) 0.06-0.49) and thus far below the 


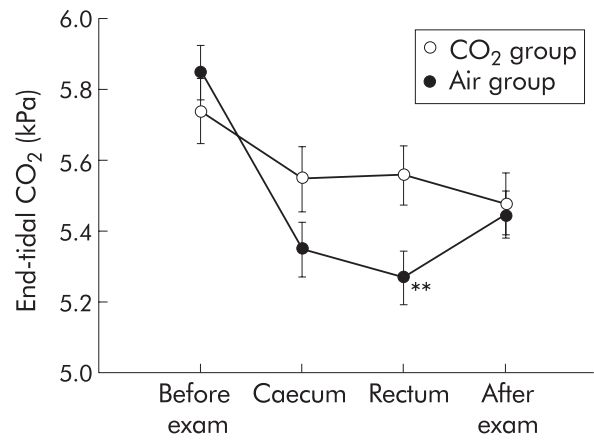

Figure 1 Mean (SEM) end-tidal $\mathrm{CO}_{2}$ values at the various observation points in the $\mathrm{CO}_{2}(\mathrm{n}=75)$ and air $(\mathrm{n}=81)$ groups. ${ }^{*} \mathrm{p}=0.01$ compared with the $\mathrm{CO}_{2}$ group at the corresponding time point by repeated measures ANOVA with multiple comparisons.

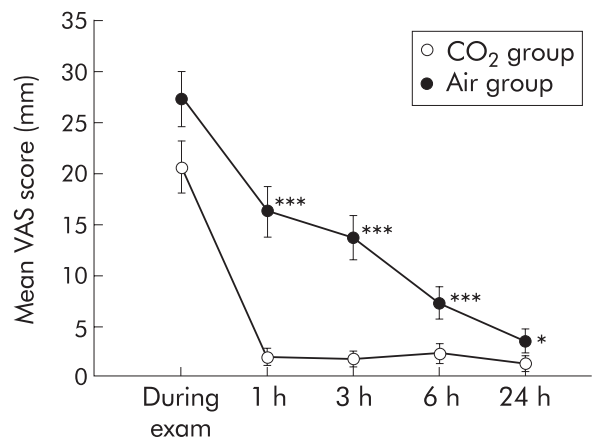

Figure 2 Mean (SEM) visual analogue scale (VAS) scores at the various observation points during and after examination in the $\mathrm{CO}_{2}$ $(n=121)$ and air $(n=119)$ groups. ${ }^{*} p<0.05,{ }^{* * *} p<0.001$ compared with the $\mathrm{CO}_{2}$ group at corresponding time points by the Wilcoxon rank sum test.

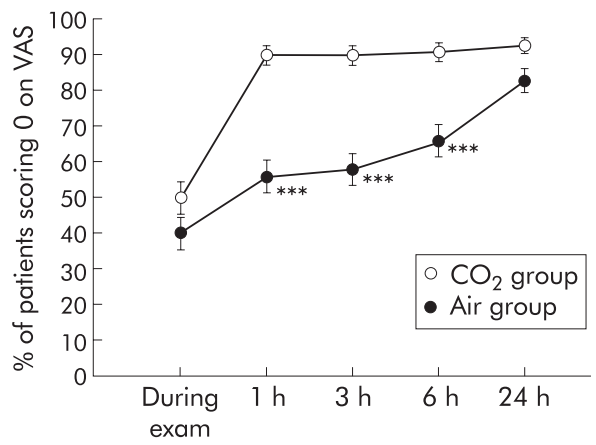

Figure 3 Percentage of patients in the $\mathrm{CO}_{2}(\mathrm{n}=121)$ and air ( $n=119)$ groups who scored $O$ (no pain) on the visual analogue scale (VAS) at the observation points during and after examination. Values are mean (SD). ${ }^{* * *} p<0.001$ compared with the $\mathrm{CO}_{2}$ group at corresponding time points by the $\chi^{2}$ test.

limit of clinical relevance $(0.5 \mathrm{kPa})$. Non-parametric analyses at each time point supported these findings.

\section{Pain during and after examination}

Figure 2 shows mean pain scores in each group during and after the examination. There were statistically significant differences in pain scores, favouring $\mathrm{CO}_{2}$ insufflation at all observed time points after examination. The overall mean difference was $7.8 \mathrm{~mm}$ (95\% CI 4.4-11.2) $(\mathrm{p}<0.001)$. The pain reduction after examination was significantly more rapid in the $\mathrm{CO}_{2}$ group $(\mathrm{p}=0.003)$. The maximum difference ( $14 \mathrm{~mm}$ (95\% CI 9-19); $p<0.001)$ was observed one hour after the examination. Comparison of the two groups by non- parametric analysis at each separate time point gave results similar to the overall analysis.

An alternative visualisation of the pain score results is to compare the proportion of patients with score zero (no pain) on the VAS. Figure 3 shows these proportions at each measurement. The finding of a clinically relevant difference in pain, favouring the use of $\mathrm{CO}_{2}$, was supported.

\section{DISCUSSION}

This randomised double blind trial in unsedated patients showed that $\mathrm{CO}_{2}$ insufflation during colonoscopy reduced the amount of pain during and after the examination. No rise in $\mathrm{ETCO}_{2}$ during or after the examination was registered.

The caecum reach ratio in this trial $(90 \%)$ was somewhat lower than the rates probably expected in colonoscopy performed by experienced endoscopists. ${ }^{7}$ It must be pointed out that the participants in the present trial were different from patients attending a normal hospital endoscopy unit. They were asymptomatic, with adenomas discovered at screening FS, most of a size not even qualifying for colonoscopy in other FS screening trials. ${ }^{9}$ In addition, any spread of information in the community about painful colonoscopies would probably influence compliance for both screening and later surveillance. The endoscopists in this trial would therefore be more inclined to discontinue the examination if pain was inflicted during the procedure.

\section{Pain during and after examination}

Although a VAS scale is considered to be a reliable method for assessment of patient's pain, ${ }^{10}$ it has been claimed that more patients fail to score on a VAS scale compared with other pain registration methods. ${ }^{11}$ However, in the present study $93 \%$ of the questionnaires were returned, all completed.

The observed mean difference between the $\mathrm{CO}_{2}$ and air groups regarding pain perception was less than the predefined $15 \mathrm{~mm}$ on the VAS scale considered to be clinically important (fig 2). However, in the $\mathrm{CO}_{2}$ group, more than $90 \%$ of patients reported that they were completely free from pain after the examination whereas in the air group more than $40 \%$ of patients reported pain during the first hours after the procedure (fig 3). In our opinion, this difference is large enough to be clinically relevant and shows clearly the superiority of $\mathrm{CO}_{2}$ compared with air regarding patient pain.

As far as we aware, only one study has been published comparing pain perception using $\mathrm{CO}_{2}$ and air insufflation in colonoscopy. ${ }^{12}$ The authors reported statistically significant reductions in the amount of pain in favour of $\mathrm{CO}_{2}$ at both six and 24 hours after the examination. In their study, all patients received analgesia (meperidine) and a sedative (diazepam) prior to and during the examination. As diazepam has a long lasting effect with a half life of more than 24 hours, sedation amnesia may influence the validity of scores given. ${ }^{13}$ In our trial, patients receiving sedation were excluded from analysis; hence the VAS scores and $\mathrm{ETCO}_{2}$ measurements were not influenced by sedation. However, the results of the two studies are similar with a reduction in pain using $\mathrm{CO}_{2}$.

In the present study the use of sedation differed between the two groups, with more individuals in the air group requiring sedation. If these patients had not been excluded from the present analyses, the observed differences would have been somewhat larger. Although the need for on demand administration of sedation in this study was judged subjectively by the endoscopist, the endoscopist's observation of the patient's need was consistent with the differences between the groups in VAS scores given by the patients.

\section{End-tidal $\mathrm{CO}_{2}$}

The ideal gas for insufflation during colonoscopy should be inert. However, this gas has yet to be found. $\mathrm{CO}_{2}$ is not ideal as it interferes with normal metabolic processes. It has been 
known for a long time that intraperitoneal $\mathrm{CO}_{2}$ insufflation during laparoscopic surgery causes a rise in arterial $\mathrm{pCO}_{2}$ levels ${ }^{45}$ but this side effect is probably less marked in retroperitoneal compared with intraperitoneal insufflation. ${ }^{14}$ Furthermore, a laparoscopic procedure is quite different from colonoscopy (mechanical ventilation, Trendelenburg position, $\mathrm{CO}_{2}$ kept under a positive pressure). ${ }^{3}$ Therefore, there was a need to investigate the effect on $\mathrm{pCO}_{2}$ during insufflation of $\mathrm{CO}_{2}$ in colonoscopy. To measure arterial $\mathrm{pCO}_{2}$, arterial blood samples are needed. This was considered impractical in the present study. We used $\mathrm{ETCO}_{2}$ measurement as an approximation of arterial $\mathrm{pCO}_{2}$. Continuous measurement of $\mathrm{ETCO}_{2}$, often through a nasal or nasopharyngeal canula, has been the preferred method in other studies. ${ }^{815}$ In the present study patients were awake, non-sedated, and would probably not have tolerated such canulae. We therefore measured $\mathrm{ETCO}_{2}$ repeatedly using a mouthpiece connected to a capnograph. This method may not be as accurate as those published previously but it is an easily performed approximation to arterial $\mathrm{pCO}_{2}$ in this setting. The purpose of our measurements was to exclude a clinically significant rise in body $\mathrm{CO}_{2}$ level, not to evaluate exact values within the reference area.

We did not detect any rise in $\mathrm{ETCO}_{2}$ levels. On the contrary, we observed an overall decrease in $\mathrm{ETCO}_{2}$ during and after the procedure, slightly more marked in the air group. A possible explanation for this is that patients may have hyperventilated during the procedure, and that insufflation of $\mathrm{CO}_{2}$ to some extent outweighed this reduction in $\mathrm{ETCO}_{2}$. Rogers reported a rise, although not statistically significant, in arterial $\mathrm{pCO}_{2}$ during colonoscopy. ${ }^{16}$ In that study, all patients were sedated and sedation is known to cause changes in $\mathrm{pCO}_{2}$ and other metabolic parameters. ${ }^{17}$ Hence these results are difficult to compare with ours.

No patient with severe heart or lung diseases (NYHA III-IV) was included in this study. Therefore, our results cannot be generalised to these patient categories. The safety for these patients and for sedated patients has to be investigated further before extending recommendations to other than our described patient population.

\section{CONCLUSIONS}

This randomised trial of unsedated patients showed that $\mathrm{CO}_{2}$ insufflation during colonoscopy is safe with no rise in $\mathrm{ETCO}_{2}$ levels. $\mathrm{CO}_{2}$ was found to be superior to air regarding pain after the examination. In this study, $\mathrm{CO}_{2}$ insufflation led to an almost complete absence of post examination pain. We recommend $\mathrm{CO}_{2}$ insufflation in colonoscopy.

\section{ACKNOWLEDGEMENTS}

We thank the nurses at the NORCCAP centre without whose enthusiastic support this study would not have been possible. The trial was supported financially by the Norwegian Department of Health and Social Affairs, the Norwegian Cancer Society, the Norwegian Gastroenterological Association, and Endotronic Ltd. The study was presented in part at the UEGW 2000 in Brussels.

\section{Authors' affiliations}

M Bretthauer, E Thiis-Evensen, G Huppertz-Hauss, G Hoff, NORCCAP-Centre, Telemark Central Hospital, Porsgrunn, Norway L Gisselsson, Department of Anaesthesiology, Telemark Central Hospital, Porsgrunn, Norway

T Grotmol, The Cancer Registry of Norway, Oslo, Norway

E Skovlund, Section of Medical Statistics, University of Oslo, Oslo, Norway

\section{REFERENCES}

1 Carter HG. Explosion in the colon during electrodesiccation of polyps. Am J Surg 1952;11:514-16.

2 Becker GL. Prevention of gas explosions in the large bowel during electrosurgery. Surg Gynecol Obstet 1953;97:463.

3 Williams CB. Who's for $\mathrm{CO}_{2}$ ? Gastrointest Endosc 1986;32:365-7.

4 Magno R, Medegard A, Bengtsson R, et al. Acid base balance during laparoscopy: The effect of intraperitoneal insufflation of carbon dioxide and nitrous oxide on acid-base balance during controlled ventilation. Acta Obstet Gynecol Scand 1979;58:81-5.

5 Wolf JS Jr. Pathophysiologic effects of prolonged laparoscopic operation. Semin Surg Oncol 1996;12:86-95.

6 Podolsky DK. Going the distance-The case for true colorectal cancer screening. N Engl J Med 2000;343:207-8.

7 Hoff G. Colonoscopy without sedation. Scand J Gastroenterol 2000;35:225-6.

8 Goldman JM. A simple, easy, and inexpensive method for monitoring ETCO2 through nasal canulae. Anesthesiology 1987;67:606.

9 Atkin WS, Edwards R, Wardle J, et al. UK randomized trial of once-only flexible simoidoscopy screening: baseline results. Endoscopy 1999;31(suppl 1):E1.

10 Revill SI, Robinson JO, Rosen $M$, et al. The reliability of a linear analogue for evaluating pain. Anaesthesia 1976;31:1191-8.

11 Kremer E, Hampton Atkinson J, et al. Measurement of pain: patient preference does not confound pain measurement. Pain 1981;10:241-8.

12 Stevenson GW, Wilson JA, Wilkinson J, et al. Pain following colonoscopy: elimination with carbon dioxide. Gastrointest Endosc 1992;38:564-7.

13 Ladas SD. Factors predicting the possibility of conducting colonoscopy without sedation. Endoscopy 2000;32:688-92.

14 Giebler RM, Kabatnik M, Stegen BH, et al. Retroperitoneal and intraperitoneal $\mathrm{CO}_{2}$ insufflation have markedly different cardiovascular effects. J Surg Res 1997;68:153-60.

15 Turner KE, Sandler AN, Vosu HA. End-tidal CO2 monitoring in spontaneously breathing adults. Can J Anaesth 1989:36:248-9.

16 Rogers BHG. The safety of carbon dioxide insufflation during colonoscopic electrosurgical polypectomy. Gastrointest Endosc 1974;20: 1 15-17.

17 Bell GD. Premedication, preparation, and surveillance. Endoscopy 2000;32:92-100. 